\title{
Characterization of phosphorus in the aerosol of a coastal atmosphere: Using a sequential extraction method
}

\author{
Hung-Yu Chen ${ }^{\mathrm{a}, *}$, Tien-Hsi Fang ${ }^{\mathrm{a}}$, Martin R. Preston ${ }^{\mathrm{b}}$, Saulwood Lin ${ }^{\mathrm{c}}$ \\ ${ }^{a}$ Department of Marine Environmental Informatics, National Taiwan Ocean University, Keelung 202, Taiwan \\ ${ }^{\mathrm{b}}$ Department of Earth and Ocean Sciences, University of Liverpool, 4 Brownlow Street, Liverpool L69 3GP, UK \\ ${ }^{\mathrm{c}}$ Institute of Oceanography, National Taiwan University, Taipei 106, Taiwan
}

Received 12 March 2005; received in revised form 8 September 2005; accepted 12 September 2005

\begin{abstract}
Particulate aerosol was sequentially extracted by citrate/dithionite/bicarbonate and acetic acid/sodium acetate buffers so as to isolate phosphorus associated with oxides/hydroxides (Fe-P) and Acet-P, respectively. Total phosphorus (TP) and total inorganic phosphorus (TIP) contents were analyzed separately and the difference between them used to calculate the organic phosphorus (OP) content. The difference between TIP and the sum of Fe-P and Acet-P was assumed to be the detrital apatite (Det-P). The results of this study indicate that phosphorus species show a clear monthly variability that is related to the source strengths of the crustal weathering and biological blooming in winter and spring, respectively. There are highly significant covariations between the TP, TIP and Det-P, which suggests that these derive from similar sources and share transport mechanisms. The percentage concentrations of OP show that phosphorus tends to be associated with organic particles in warm periods when biological activity is greatest.
\end{abstract}

(C) 2005 Elsevier Ltd. All rights reserved.

Keywords: Phosphorus; Inorganic phosphorus; Organic phosphorus; Aerosol; Sequential extraction method

\section{Introduction}

Phosphorus $(\mathrm{P})$ is one of essential micronutrients in both marine and freshwater ecosystems (Chester, 2002; Huanxin et al., 1997). In coastal areas, the supply of $\mathrm{P}$ is mainly dominated by riverine and atmospheric inputs (Fang, 2004). With the increasing fluxes from anthropogenic sources, atmospheric inputs of nutrients are believed to cause significant effects within coastal ecosystems (de Leeuw et al., 2003; Cornell et al., 2003). Béthoux et al. (1998)

\footnotetext{
*Corresponding author. Fax: + 886224621047.

E-mail address: hychen@mail.ntou.edu.tw (H.-Y. Chen).
}

indicated that the inputs of total $\mathrm{P}$ in the Atlantic Ocean derive primarily from riverine inputs $(\sim 90 \%)$ with the remaining $10 \%$ coming from atmospheric sources. The relative degrees of riverine inputs decreased with increasing distance from land, so atmospheric inputs of $\mathrm{P}$ played a major role on the biogeochemical processes of some oligotrophic surface seawaters (Markaki et al., 2003; Pan et al., 2002).

The concentrations of particulate $\mathrm{P}$ are therefore important because atmospheric deposition may be biologically significant (Arimoto et al., 1989). However, in most atmospheric studies, $\mathrm{P}$ is treated as an insoluble species and assumed to enter the 
atmosphere from a variety of sources including dust, sea spray or plant pollen (Graham and Duce, 1979). The results of previous studies (Migon et al., 2001; Herut et al., 1999) show that $\mathrm{P}$ associated with continental-derived dusts, and which is therefore classified as detrital $\mathrm{P}$, exhibits low solubility. The flux of $\mathrm{P}$ to the marine environment resulting from dissolution from eolian dust has been estimated to be $3 \times 10^{9} \mathrm{~mol} \mathrm{Pyr}^{-1}$ which represents about $10 \%$ of river fluxes to the ocean (Delaney, 1998). Markaki et al. (2003) reported that up to $38 \%$ of new production in the eastern Mediterranean was supported by the inorganic phosphorus (DIP) dissolved from eolian dusts. This study was however, based on the water soluble fraction of atmospheric $\mathrm{P}$ and may therefore have underestimated total fluxes of phosphorus by ignoring the insoluble components.

To understand the behaviors of $\mathrm{P}$ in the atmosphere and its subsequent behavior after deposition, it is clearly necessary to identify the phases of $\mathrm{P}$ within particulate aerosols (Markaki et al., 2003). Ruttenberg (1992) indicated that a sequential extraction technique (SEDEX) is the most appropriate method to separate and quantify the various $P$ reservoirs. Briefly, a sequential extraction technique that uses different chemical reagents and analytical treatments allows five phases of $\mathrm{P}$ to be identified in sediments, namely adsorbed, oxideassociated, authigenic, detrital and organic phases. During the past decade, the SEDEX approach has mostly been focused on the phase distributions of $\mathbf{P}$ in marine sediments (Ruttenberg, 1993; Eijsink et al., 1997; Anderson and Delaney, 2000). Berner and Rao (1994) have modified this method to identify five different forms Fe-P, acet-P (authigenic calcium phosphate, bone apatite and $\mathrm{P}$ adsorbed to calcium carbonate), detrital $\mathrm{P}$, organic $\mathrm{P}$ and total $\mathrm{P}$. The advantage of this method is that the different phases of $\mathrm{P}$ can be analyzed by three independent procedures which provide confident and reliable estimates of the $\mathrm{P}$ abundance achieved and, therefore, the modified SEDEX may be a new approach to identify the different cataloges of $\mathrm{P}$ in particulate aerosols.

Although many efforts have been devoted to the study of $\mathrm{P}$ distributions and biogeochemical transformation mechanisms in sediments, equivalent studies of $\mathrm{P}$ in the aerosols still rare, particularly those that are related to the behavior of the $\mathrm{P}$ cycle in the atmosphere. In this paper, we report the first application of SEDEX to the study of the phases of
$\mathrm{P}$ in particulate aerosols leading to a significant improvement to the understanding of the nature and behavior comprehension of sources of this species in the marine atmosphere.

\section{Methods}

\subsection{Sampling}

The sampling site was located on the roof of a building at the National Taiwan Ocean University $\left(25.09^{\prime} \mathrm{N} ; 121.46^{\prime} \mathrm{E}\right)$ close to the East China Sea. The roof is $25 \mathrm{~m}$ height from ground level $(57 \mathrm{~m}$ from sea level) and $40 \mathrm{~m}$ far from the nearest main road. A high volume air sampling system (hi-vol) (Tisch TE5170; Tisch Environmental, Inc., Ohio) was utilized to collect particulate aerosols in this study. Also the meteorological station supplied temperature, wind speed and direction data.

Total particulate aerosol samples were collected using a standard glass fiber filter (WhatmanEPM2000; $203 \times 254 \mathrm{~mm})$. These filters have a reported collection efficiency of $99.998 \%$ for 0.3-0.4 $\mu \mathrm{m}$ particles. Before use the filters were ashed at $350{ }^{\circ} \mathrm{C}$ for $24 \mathrm{~h}$ and then loaded into the filter holders under clean (laminar flow) conditions. The flow rate was set at $0.8 \mathrm{~m}^{3} \mathrm{~min}^{-1}$ and total sampling time was $24 \mathrm{~h}$ to achieve a total sampling air volume of about $1150 \mathrm{~m}^{3}$ of air. The sampling period of particulate aerosol was from September 2003 to June 2004 (due to a mechanical problem, no aerosol samples were collected in November 2003) and a total of 27 samples were collected. Three random samples were selected to be analyzed for each month. After sampling, the filter was freeze dried and weighed by a balance equipped with a standard filter size weighing pan (AB204-S; Mettler Toledo) to calculate the total suspended particle (TSP) load by difference. The samples were stored in the freezer at $-24{ }^{\circ} \mathrm{C}$ before futher analysis.

\subsection{Chemical analysis}

The extraction method used was based on the SEDEX method of Ruttenberg (1993) as modified by Berner and Rao (1994). Every standard filter was cut equivalent into 4 separate subsamples, and 3 of these 4 pieces were then used to analyze the individual phase of $\mathrm{P}$.

The first subsample (Sample A) was extracted by a $30 \mathrm{~mL}$ of citrate/dithionite/bicarbonate (CDB) mixture solution $\left(0.3 \mathrm{M} \mathrm{C}_{6} \mathrm{H}_{5} \mathrm{Na}_{3} \mathrm{O}_{7}+1 \mathrm{M}\right.$ 
$\left.\mathrm{NaHCO}_{3}+0.06 \mathrm{M} \mathrm{Na}_{2} \mathrm{~S}_{2} \mathrm{O}_{4}\right)$ at $\mathrm{pH}$ 7.6. Ruttenberg (1993) and Berner and Rao (1994) have defined this phase as exchangeable and reactive ferric bound $\mathrm{P}$ (Fe-P). After CDB extraction, the residue was washed with $30 \mathrm{~mL}$ of Milli-Q water to remove any residual CDB solution. The residue of Sample A was then extracted with a $30 \mathrm{~mL}$ of acetate buffer solution (acetic acid/sodium acetate; $1 \mathrm{M} \mathrm{CH}_{3} \mathrm{COO}$ $\mathrm{Na}$ buffered to $\mathrm{pH} 4$ with acetate acid). The Acet-P represents authigenic calcium phosphate, bone apatite, and $\mathrm{P}$ adsorbed to calcium carbonate (Berner and Rao, 1994).

The second subsample (Sample B) was extracted by $20 \mathrm{~mL}$ of $1 \mathrm{~N} \mathrm{HCl}$ without ashing (Aspila et al., 1976; Berner and Rao, 1994) and classified as total inorganic P (TIP). The third subsample (Sample C) which is identified as total P (TP), was ashed overnight at $550{ }^{\circ} \mathrm{C}$ and then extracted with $20 \mathrm{~mL}$ of $1 \mathrm{~N} \mathrm{HCl}$ (Aspila et al., 1976; Berner and Rao, 1994). The organic P (OP) content was then calculated as the difference between TP and TIP. The detrital apatite (Det-P) was also calculated as the difference between TIP and the sum of Fe-P and Acet-P according to the rationale of Berner and Rao (1994).

In each case, the phosphorus content was measured on filtered extracts on a Perkin-Elmer Lambda Bio 20 spectrophotometer as phosphate with a $5-\mathrm{cm}$ quartz cell using the molybdate blue method by adding $2 \mathrm{~mL}$ of molybdate reagent and

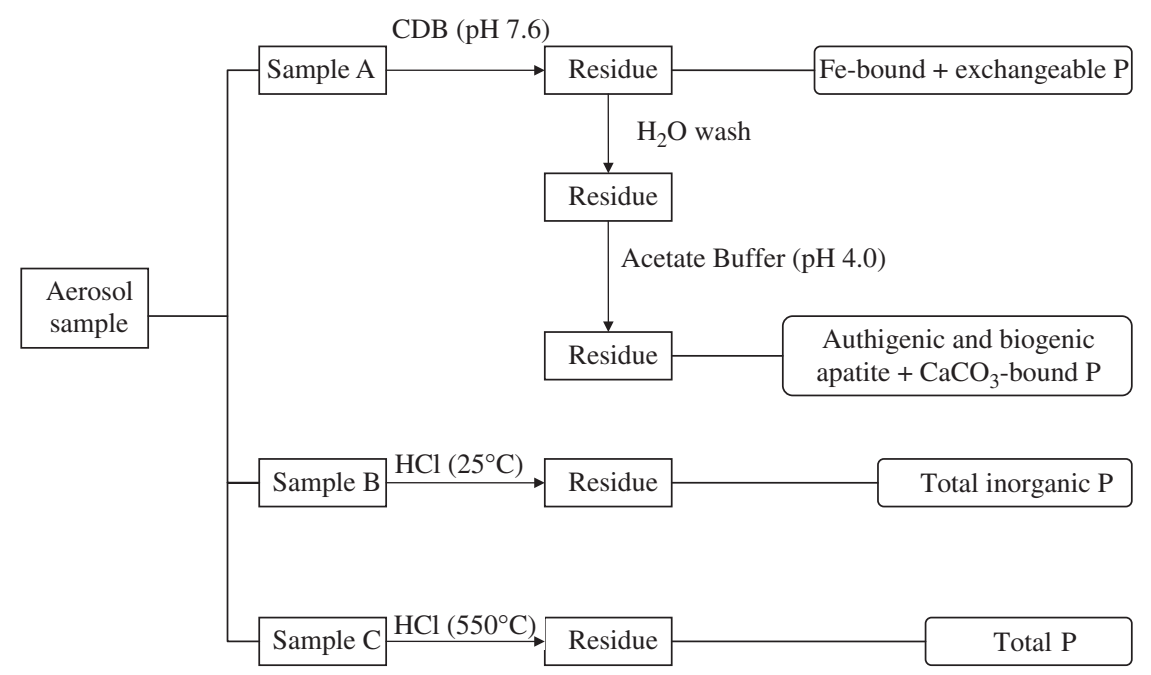

Fig. 1. Analytical scheme for the selective extraction method used for different forms of $\mathrm{P}$ in particulate aerosols.

Table 1

Budget of phosphorus species in total suspended particles

\begin{tabular}{lccccc}
\hline & Mninum & Maximum & Median & Mean & Standard deviation \\
\hline TP $^{\mathrm{a}}$ & 0.56 & 5.06 & 1.28 & 1.49 & 0.94 \\
$\mathrm{TIP}^{\mathrm{a}}$ & 0.41 & 4.78 & 1.01 & 1.20 & 0.89 \\
$\mathrm{Fe}^{\mathrm{a}}$ & 0.03 & 0.31 & 0.07 & 0.10 & 0.07 \\
Acet-P $^{\mathrm{a}}$ & 0.001 & 0.020 & 0.003 & 0.004 & 0.004 \\
Det-P $^{\mathrm{a}}$ & 0.38 & 4.45 & 0.89 & 1.10 & 0.82 \\
OP $^{\mathrm{a}}$ & 0.02 & 0.80 & 0.25 & 0.30 & 0.20 \\
TIP/TP & 59.6 & 98.2 & 78.9 & 78.7 & 9.81 \\
Fe-P/TP & 4.41 & 10.0 & 6.03 & 6.27 & 1.52 \\
Acet-P/TP & 0.08 & 0.60 & 73.4 & 0.30 & 0.14 \\
Det-P/TP & 53.2 & 91.9 & 21.1 & 72.1 & 9.72 \\
OP/TP & 1.78 & 40.4 & & 21.3 & 9.81 \\
\hline
\end{tabular}

${ }^{\text {a }}$ Phosphorus species concentration expressed as $\mathrm{nmol} \mathrm{m}^{-3}$.

${ }^{\mathrm{b}}$ Contribution to total phosphorus and expressed as $\%$. 
$0.5 \mathrm{~mL}$ of ascorbic acid reagent which has been described in detail in Murphy and Riley (1962) and Pai et al. (1990).

The procedural blanks $(n=8)$ found for this study were $6.41 \pm 0.40,5.18 \pm 0.29,0.68 \pm 0.029$ and $1.00 \pm 0.62 \mathrm{nM}$ for TP, TIP, Fe-P and Ace-P, respectively, yielding detection limits by taking 4.65 times the standard deviation of the blanks of ca. 1.9, 1.4, 0.14 and $0.29 \mathrm{nM}$ for TP, TIP, Fe-P and Acet-P, respectively. The high balank values occupied about $1.68 \%, 2.11 \%, 1.48 \%$ and $25 \%$ of the lowest real samples of TP, TIP, Fe-P and Acet-P, respectively. A modified scheme of the sequential extraction method is illustrated in Fig. 1. Full details of the analytical procedures employed can be found in Berner and Rao (1994). The data for these six phases of $\mathrm{P}$ sampled in this study are summarized and calculated in Table 1.

\section{Results and discussion}

\subsection{General characteristics of particulate aerosols}

Examination of air mass back trajectory data indicated that there were no significant inputs caused by dust storms (from the mainland China)

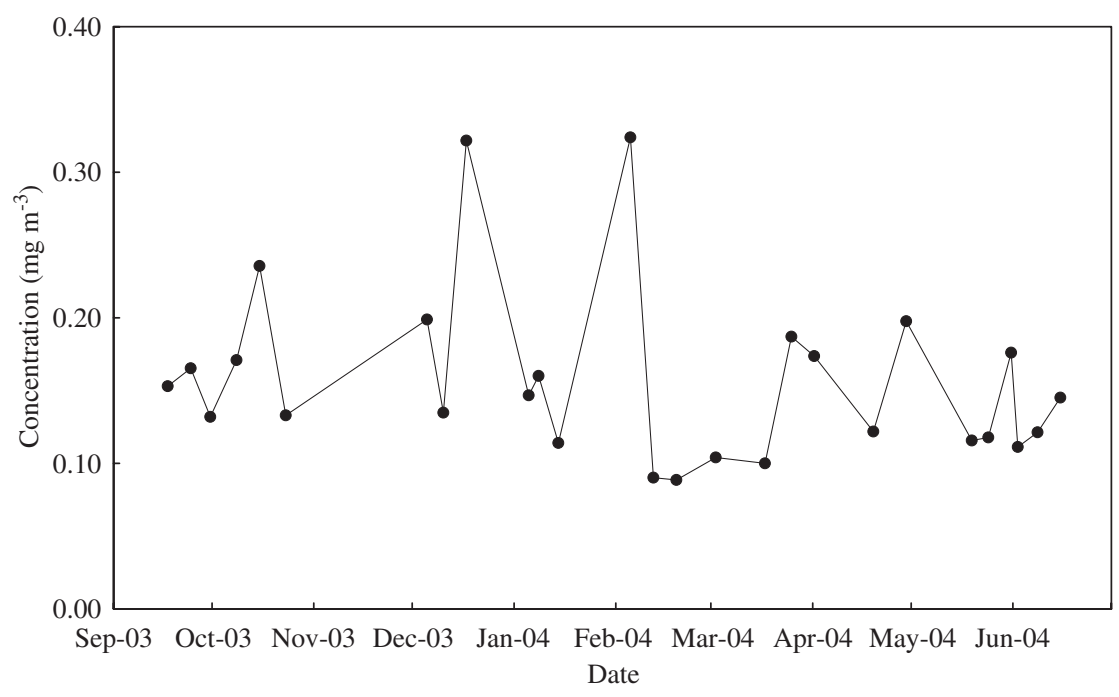

Fig. 2. Temporal variations of TSP during the sampling period of this study.

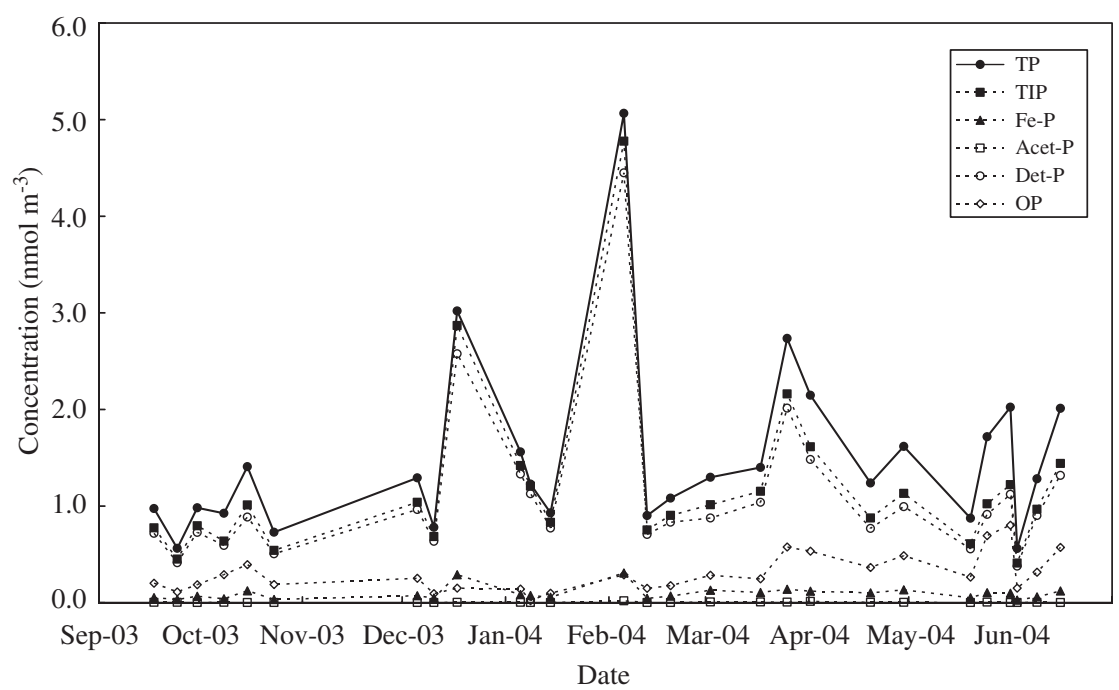

Fig. 3. Temporal variations of TP, TIP, Fe-P, Acet-P, Det-P and OP during the sampling period of this study. 
during the winter/spring of 2003/2004 although winter winds were mainely from westerly direction. During the sampling period from September 2003 to June 2004, the daily concentrations of TSP varied between 0.32 and $0.09 \mathrm{mg} \mathrm{m}^{-3}$ (Fig. 2). The maximum TSP concentrations measured $\left(0.32 \mathrm{mg} \mathrm{m}^{-3}\right)$ were on 17th December 2003 and 2nd February 2004 when back trajectories indicate passage over land to the north and northwest, and the minimum $\left(0.089 \mathrm{mg} \mathrm{m}^{-3}\right)$ on 19th February 2004 (winds from the ocean to the east) with the overall mean concentration for the whole sampling period being $0.157 \mathrm{mg} \mathrm{m}^{-3}$. Therefore, this result indicates that the mainland China plays a key role on the source transportation of the particulate matters under the monsoon system in this area. This will also affect the distribution and contribution of particulate phosphorus species in the atmsopheric environment.

\subsection{The distributions of $P$ at the sampling site}

The temporal variations in the different phases of $\mathrm{P}$ during the sampling period are shown in Fig. 3. The maximum concentrations for these parameters, except OP, occurred at the end of the winter of 2004 (February 2004) at a time of strong westerly winds that had passed over mainland China (Fig. 4(a)). In contrast, the concentrations of TP, TIP, Fe-P, Acet$\mathrm{P}$ and Det-P reached a minimum at the end of the spring or early of the summer (June 2004). For OP, the maximum concentration occurred at a time when stable easterly winds were reaching the sample site from the open Pacific Ocean (Fig. 4(b)). Overall, the percentage concentrations of individual phosphorus species in TP (Table 1) show the sequence of TIP $(60-98 \%)>$ Det-P $(53-92 \%)>$ OP $(1.8-40 \%)>$ Fe-P $(4.4-10 \%)>$ Acet-P $(<1 \%)$.

Comparing the TIP data of this study with two costal cities around the eastern Mediterranean (Markaki et al., 2003), the average concentration was $1.20 \mathrm{nmol} \mathrm{m}^{-3}$ in this study and the values were 0.43 and $0.77 \mathrm{nmol} \mathrm{m}^{-3}$ at Finokalia and Erdemli (Greece), respectively. In this study, the average concentration is apparently higher than those in the eastern Mediterranean. However, the source strength and the transport path may significantly influence the phosphorus species and their distributions in the atmosphere.

Although there are only three samples to be achieved for each month and this will result in the bias on the monthly average concentrations, especially two very high samples in December 2003 and

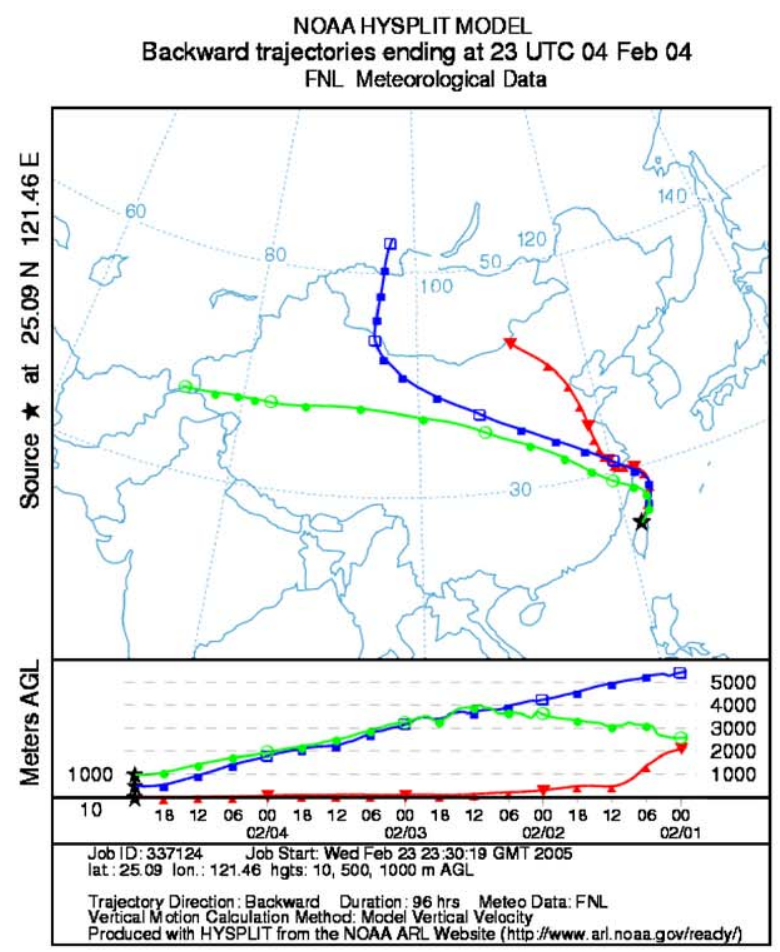

(a)

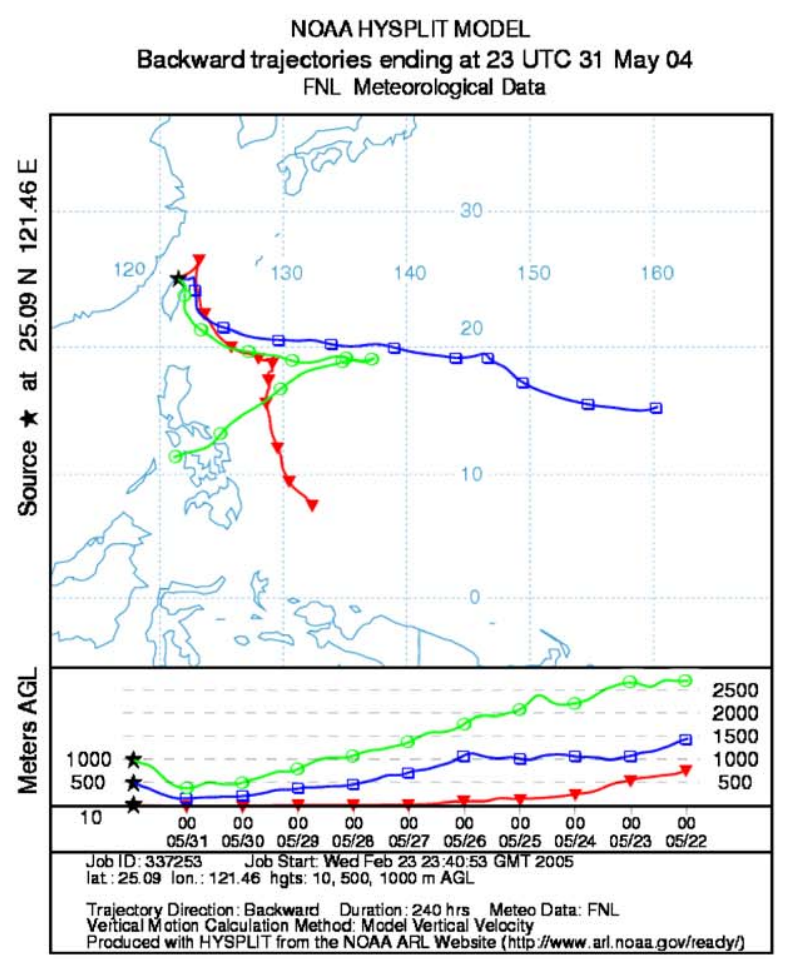

(b)

Fig. 4. Air mass back trajectories for times of maximum (a) inorganic phosphorus ( $48 \mathrm{~h}$ back trajectory) and (b) organic phosphorus ( $240 \mathrm{~h}$ back trajectory) in the aerosol. Back trajectory data obtained using the NOAA HYSPLIT model (web site http:// www.arl.noaa.gov/ready/hysplit4.html). 
NOAA HYSPLIT MODEL

Backward trajectories ending at 00 UTC 15 Sep 03 FNL Meteorological Data

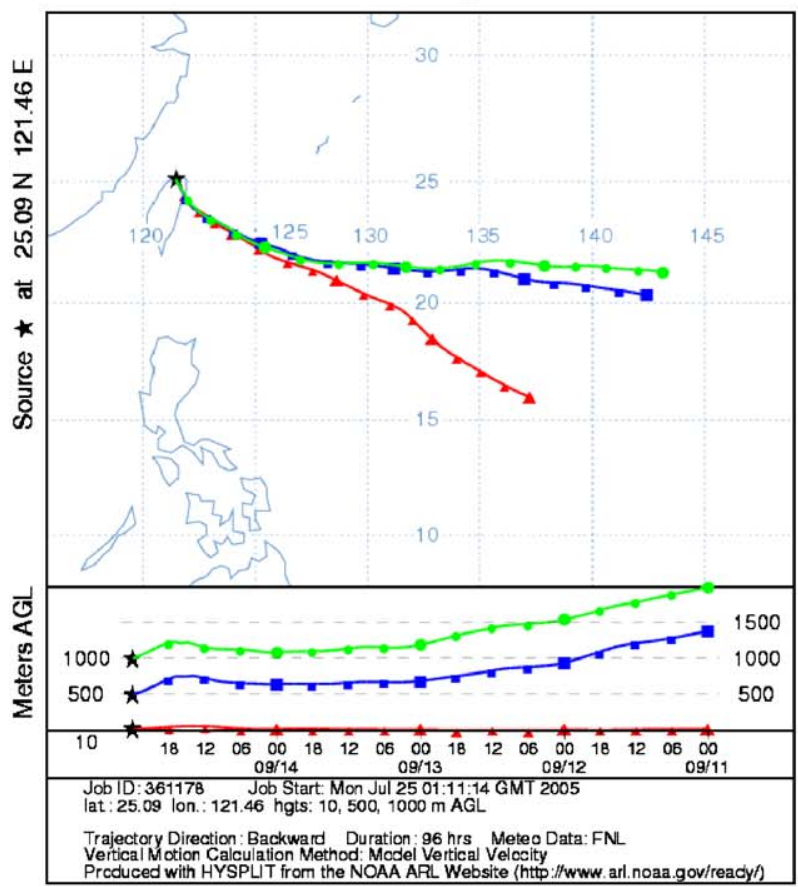

(a)

NOAA HYSPLIT MODEL

Backward trajectories ending at 00 UTC 15 Dec 03

FNL Meteorological Data

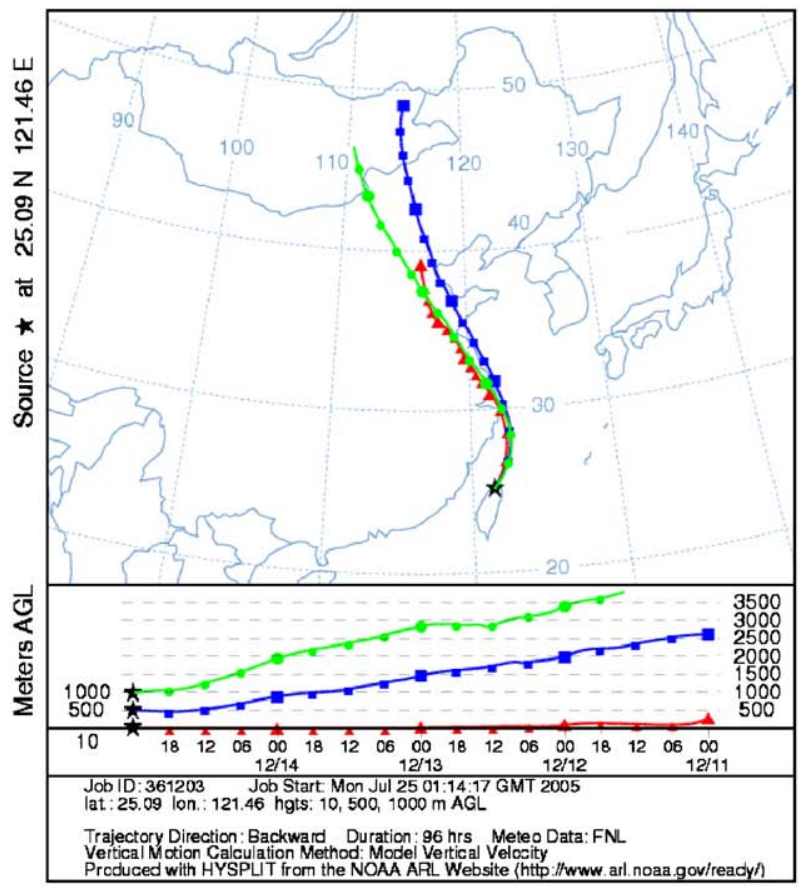

(c)
NOAA HYSPLIT MODEL

Backward trajectories ending at 00 UTC 15 Oct 03 FNL Meteorological Data

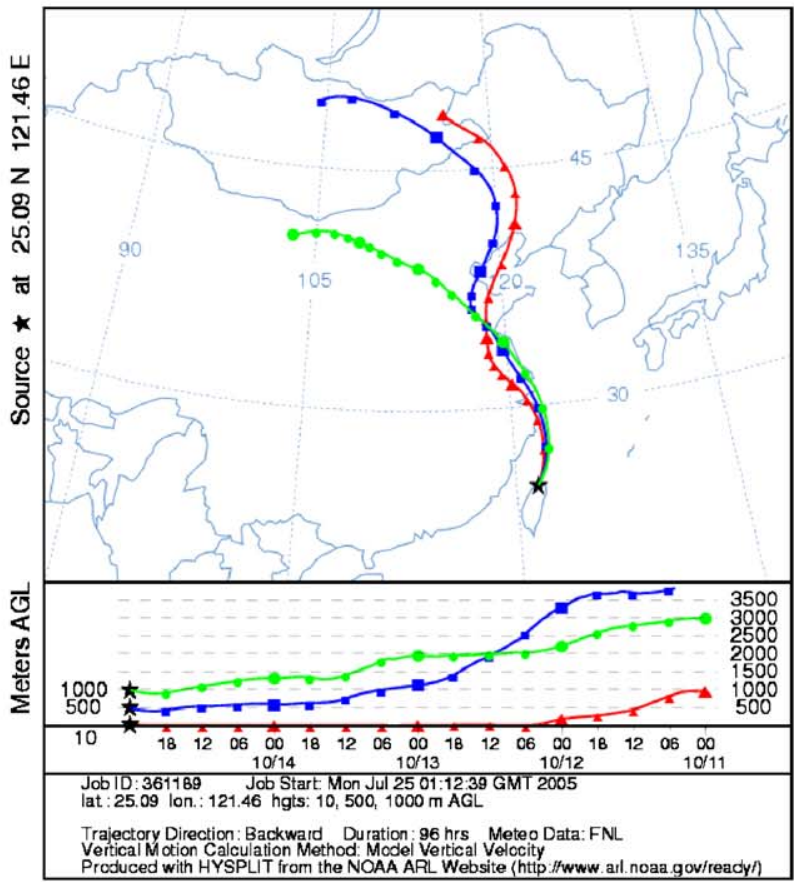

(b)

NOAA HYSPLIT MODEL

Backward trajectories ending at 00 UTC 15 Jan 04

FNL Meteorological Data

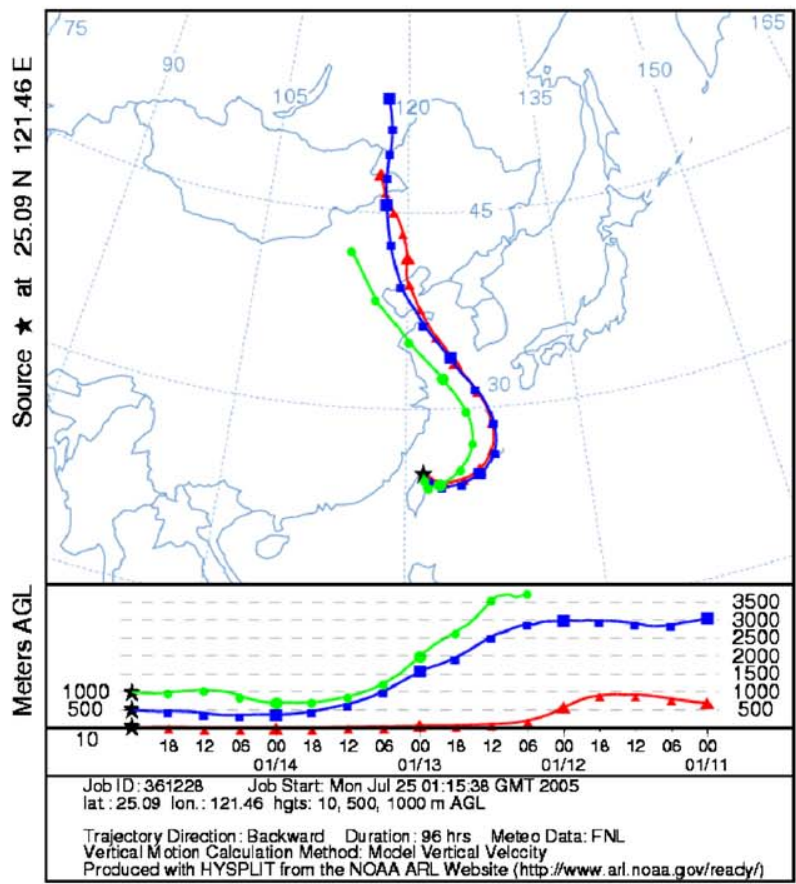

(d)

Fig. 5. The $96 \mathrm{~h}$ (4 days) air mass back trajectories for starting altitudes of 10, 500 and $1000 \mathrm{~m}$ above ground level (AGL) calculated from the FNL database of the National Ocean and Atmospheric Administration (NOAA) and simulated by using the Hybrid Single-Particle Langrangian Integrated Trajectory (HY-SPLIT) model: (a) September 2003; (b) October 2003; (c) December 2003; (d) January 2004; (e) February 2004; (f) March 2004; (g) April 2004; (h) May 2004 and (i) June 2004. 
NOAA HYSPLIT MODEL

Backward trajectories ending at 00 UTC 15 Feb 04

FNL Meteorological Data
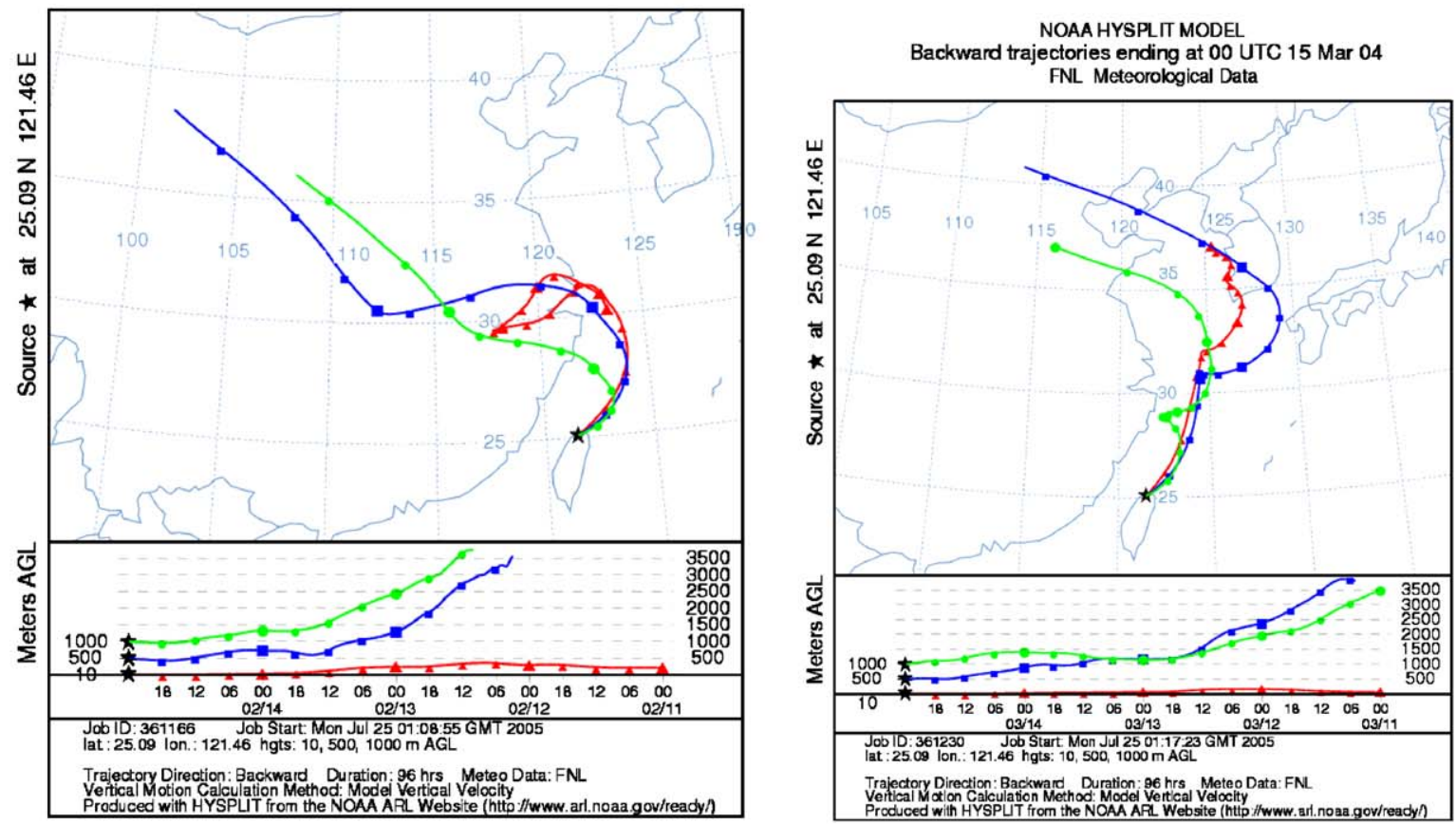

(e)

(f)

NOAA HYSPL IT MODEI

Backward trajectories ending at 00 UTC 15 Apr 04

FNL Meteorological Data

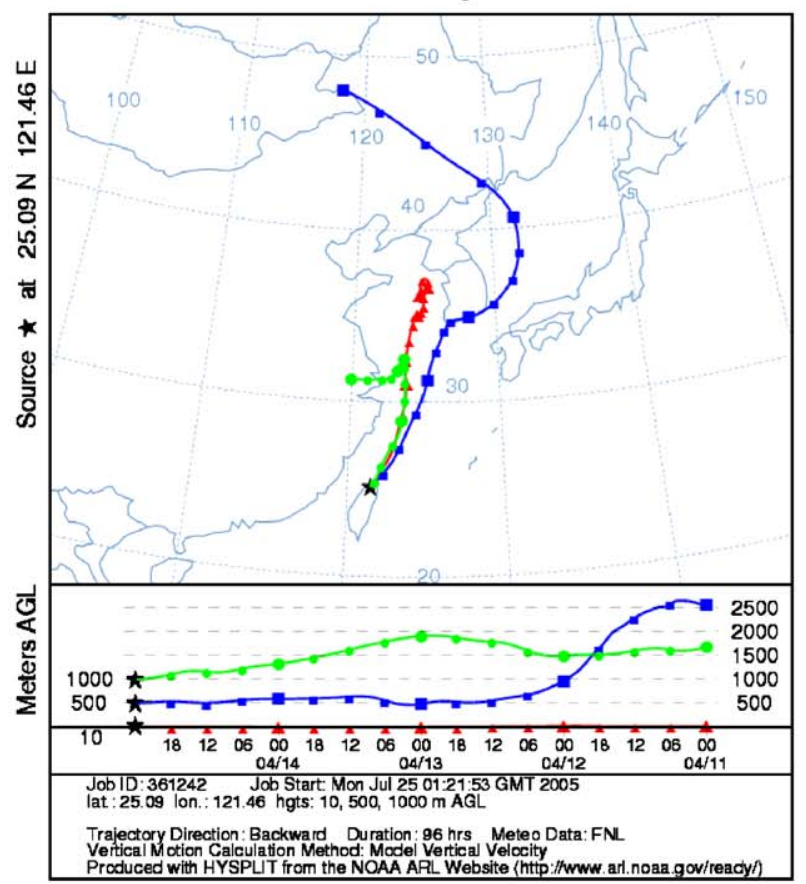

(g)

NOAA HYSPLIT MODEI

Backward trajectories ending at 00 UTC 15 May 04

FNL Meteorological Data

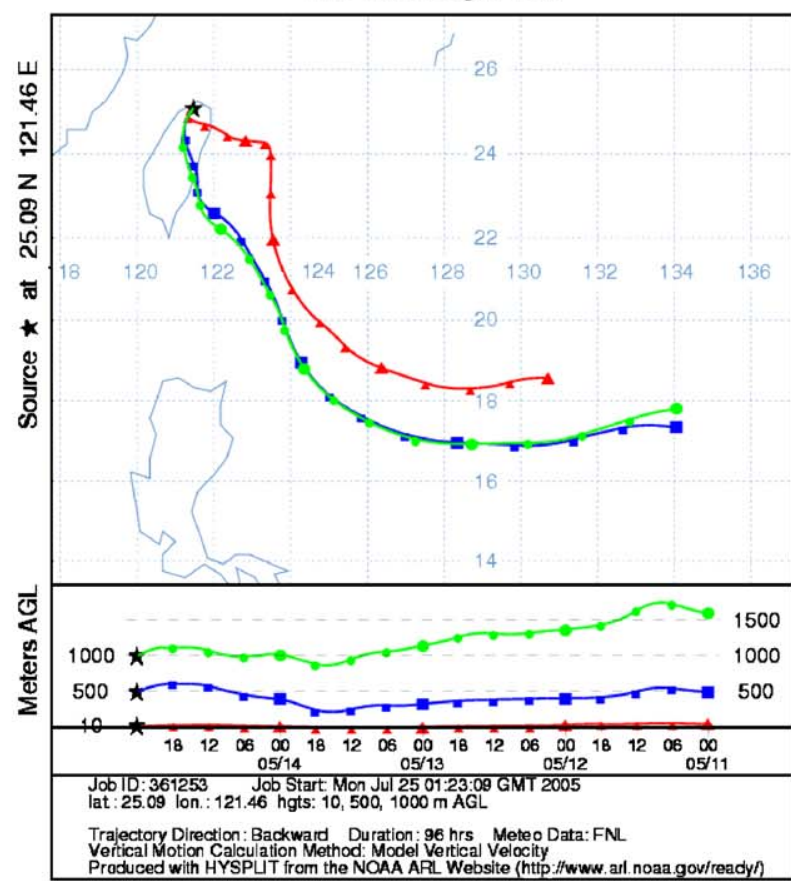

(h)

Fig. 5. (Continued) 


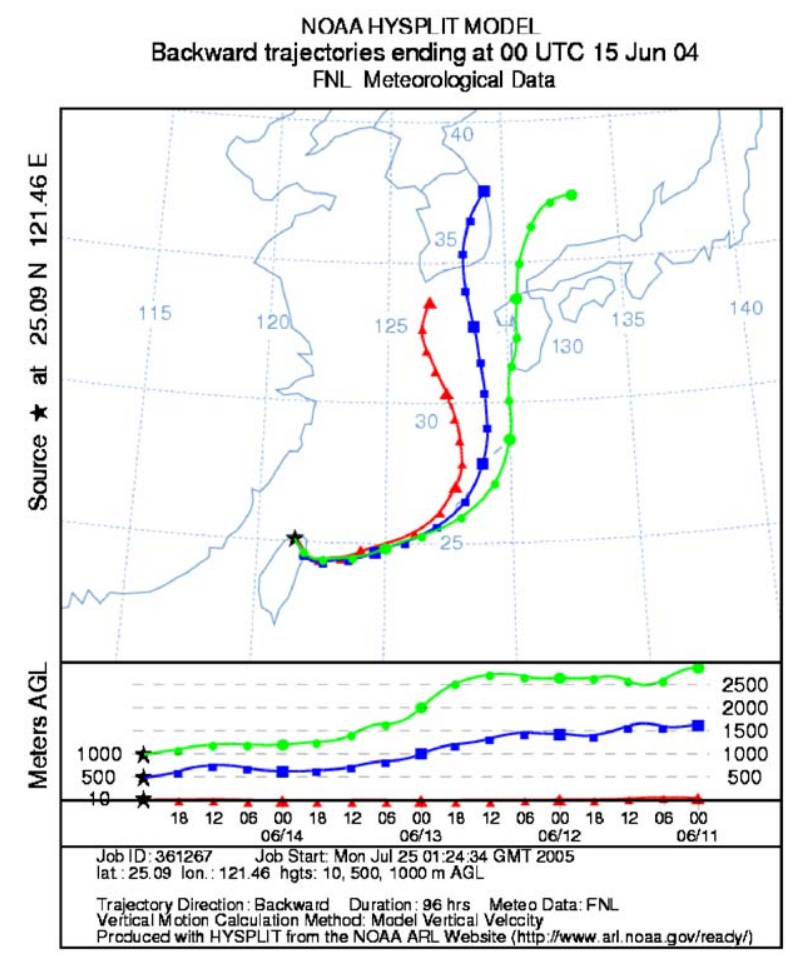

Fig. 5. (Continued)

February 2004. However, the monthly mean concentration of the phosphorus species can explain the seasonal variation over a long period of time. In this study, Air Mass Back Trajectories (AMBTs) were calculated from the National Oceanic and Atmospheric Administration (NOAA) FNL database using the Hybrid Single-Particle Langrangian Integrated Trajectories (HY-SPLIT) model (Fig. 5). The date of 15 th was selected to represent a typical model for each month. AMBTs were performed at 10,500 and $1000 \mathrm{~m}$ height levels above the ground level to represent the airflow trajectories at the surface, middle and high altitudes, respectively.

The monthly mean variations in the different inorganic phases of $\mathrm{P}$, except $\mathrm{OP}$, are shown in Fig. 6(a)-(e) and show a clear seasonal variability with mean concentrations increasing during the autumn-winter months reaching maxima in February 2004 (due to a mechanical problem fault the November 2003 samples were not obtained). After the winter of $2003 / 2004$, the monthly mean concentrations of $\mathrm{P}$ decrease, which may be the result of the reduction of the crustal source strength accompanying the decreasing of the northeastern monsoon system which usually carries a great quantity of continental material from mainland China (Fig. 5(b)-(g)).

In this study, the strong correlations were observed between TP, TIP and Det-P, suggesting the common sources and transport mechanisms for these species. The relationships and regression coefficients between these species are (correlations are significant at $p<0.01 ; n=27$ )

$$
\begin{aligned}
& {[\mathrm{TIP}]=0.936 \times[\mathrm{TP}]-0.183 \quad\left(r^{2}=0.96\right)} \\
& {[\text { Det-P }]=0.864 \times[\mathrm{TP}]-0.172 \quad\left(r^{2}=0.97\right)} \\
& {[\text { Det-P }]=0.924 \times[\text { TIP }]-0.005 \quad\left(r^{2}=0.99\right),}
\end{aligned}
$$

in which [TP] is the concentration of TP; [TIP] is the concentration of TIP; and [Det-P] is the concentration of Det-P.

As might be predicted OP presents another type of monthly mean concentration distribution (Fig. 6(f)) with concentrations decreasing during the winter months, reaching a minimum in January 2004 after which concentrations increased steadily from the late winter through the spring and reaching a maximum in May 2004. In eastern Asia, continental dust from the mainland China is one of the main contributors to the aerosol during the winter/spring period (Fig. 5(b)-(g)), especially during the period from the end of February to the beginning of April (Arimoto et al., 2004). OP is, however not the dominant phase in these aerosol samples.

Fig. 7 shows that $\mathrm{P}$ mainly exists in inorganic form which makes up to over $90 \%$ of the TP and that OP contributes $<10 \%$ of TP in the winter. This pattern may reflect the greater input of crustal $P$ during this period. During the early spring, the inputs from crustal sources decreased as a consequence of the diminution of the northeastern moonsoon system which is the main carrier for the crustal material from the mainland China and the increase contribution of marine-derived aerosol from the east (Fig. 5(h)-(i)). An additional factor is that the spring bloom in marine biomass results in the consumption of inorganic $\mathrm{P}$ by phytoplankton with the subsequent release of organic forms of $\mathrm{P}$ to the environment in the inner shelf around the East China Sea (Zhang et al., 2004; Gong et al., 2000). Due to the strong biological process, nutrient depletion and reduced terrestrial inputs the conentration of OP increases in conjunction with the decrease of IP. During this period, the fraction of OP can reach as high as nearly $40 \%$ of the TP. 

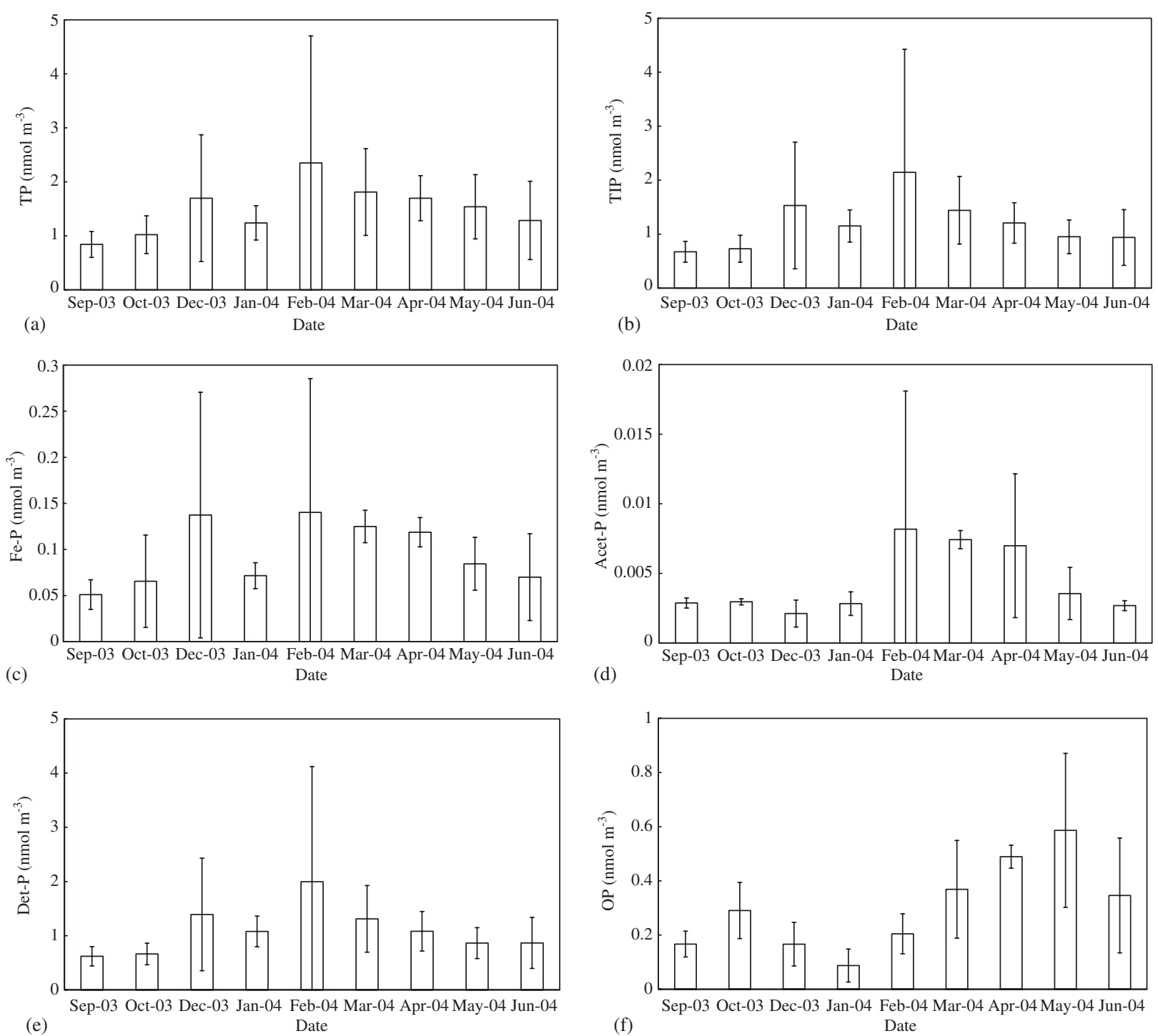

Fig. 6. The distributions of monthly mean concentration of (a) TP, (b) TIP, (c) Fe-P, (d) Acet-P, (e) Det-P and (f) OP during the sampling period of this study.

\section{Conclusions}

Marine aerosol represents a significant source of nutrient elements to the upper water column of the marine environment. This study reports the first application of a sequential leaching method to analysis of the species of phosphorus in marine aerosols. In this study, most $\mathrm{P}$ was associated with inorganic particles which were formed in the mainland China by continental weathering and then transported southward via the northeasterly monsoon system during the winter period. The strong relationships between TP, TIP and Det-P suggest that inorganic forms of $\mathrm{P}$, especially the detrital phase, dominate the behavior of $\mathrm{P}$ in the atmosphere. However, the proportion of organic phase $\mathrm{P}$ is enhanced during periods of high marine and terrestrial biological activity and/or reduced strength of the crustal source.

The measurement of $\mathrm{P}$ speciation has provided more details of the temporal variability of P-cycling marine atmosphere and its potential impact in the upper ocean. Further measurements of these species, especially the phases of TIP and OP, will help to provide new constraints on models that seek to emulate crustal source and primary production. 


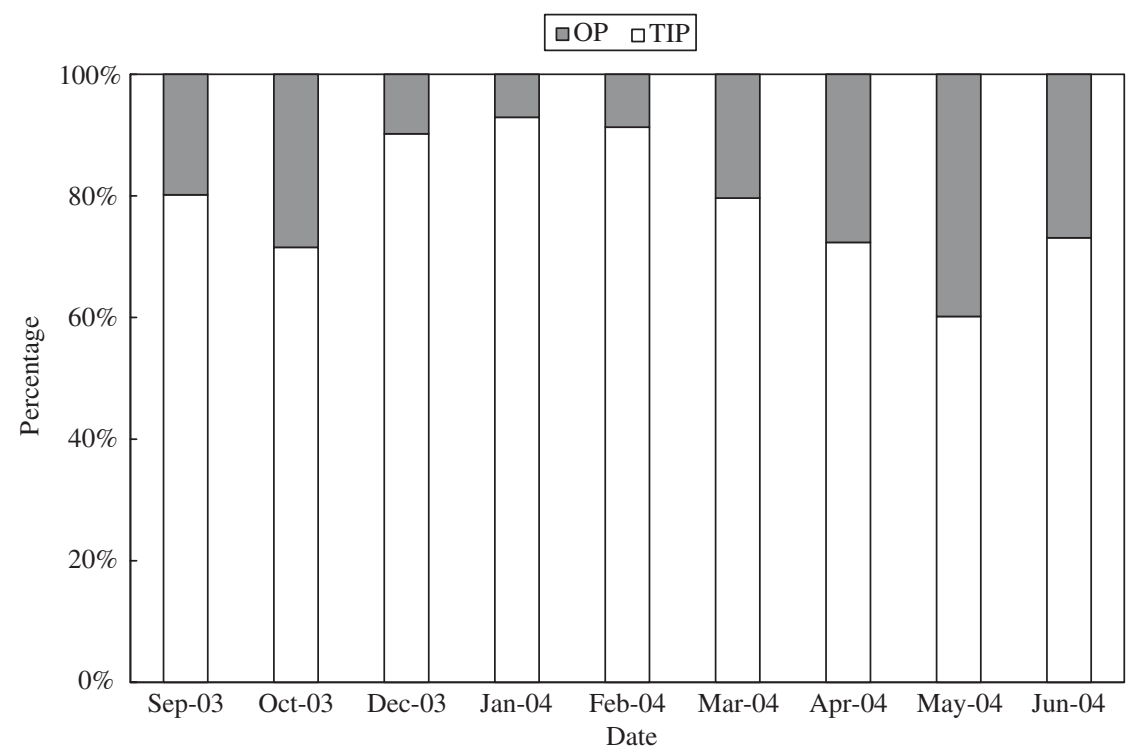

Fig. 7. The relative proportion of TIP and OP in the sampling site atmosphere.

\section{Acknowledgments}

We would like to thank the director and staffs of the Department of Oceanography (National Taiwan Ocean University) who provided full support through all the stages of this study. This work was supported by the National Science Council of Republic of China Grant No. NSC93-2611-M-019013 for HY Chen and NSC93-2611-M-019-007 for TH Fang.

\section{References}

Anderson, L.D., Delaney, M.L., 2000. Sequential extraction and analysis of phosphorus in marine sediments: streamlining of the SEDEX procedure. Limnology and Oceanography 45, 509-515.

Arimoto, R., Duce, R.A., Ray, B.J., 1989. Concentrations, sources and air-sea exchange of trace elements in the atmosphere over the Pacific Ocean. In: Riley, J.P., Chester, R. (Eds.), Chemical Oceanography, vol. 10. Academic Press, London, pp. 107-149.

Arimoto, R., Zhang, X. Y., Huebert, B. J., Kang, C. H., Savoie, D. L., Prospero, J. M., Sage, S. K., Schloesslin, C. A., Khaing, H. M., Oh, S. N. (2004). Chemical composition of atmospheric aerosols from Zhenbeitai, China, and Gosan, South Korea, during ACE-Asia. Journal of Geophysical Research-Atmosphere, 109 (D19), Art. No. D19S04.

Aspila, K.I., Agemian, H., Chau, A.S.Y., 1976. A semiautomated method for the determination of inorganic, organic and total phosphate in sediments. Analyst 101, $187-197$
Berner, R.A., Rao, J.L., 1994. Phosphorus in sediments of the Amazon River and estuary: implication for the global flux of phosphorus to the sea. Geochimica et Cosmochimica Acta 58, 2333-2340.

Béthoux, J.P., Morin, P., Chaumery, C., Connan, O., Gentili, B., Ruiz-Pino, D., 1998. Nutrients in the Mediterranean Sea, mass balance and statistical analysis of concentrations with respect to environmental change. Marine Chemistry 63, 155-169.

Chester, R., 2002. Marine Geochemistry, 2nd ed. Blackwell Publishers, London, 506pp.

Cornell, S.E., Jickells, T.D., Cape, J.N., Rowland, A.P., Duce, R.A., 2003. Organic nitrogen deposition on land and coastal environments: a review of methods and data. Atmospheric Environment 37, 2173-2191.

Delaney, M.L., 1998. Phosphorus accumulation in marine sediments and the oceanic phosphorus cycle. Global Biogeochemical Cycles 12, 563-572.

de Leeuw, G., Ambelas Skjøth, C., Hertel, O., Jickells, T., Spokes, L., Vignati, E., Frohn, L., Frydendall, J., Schulz, M., Tamm, S., Sørensen, L.L., Kunz, G.J., 2003. Deposition of nitrogen into the North Sea. Atmospheric Environment 37 (Suppl. 1), S145-S165.

Eijsink, L.M., Krom, M.D., de Lange, G.J., 1997. The use of sequential extraction techniques for sedimentary phosphorus in eastern Mediterranean sediments. Marine Geology 139, $147-155$.

Fang, T.H., 2004. Phosphorus speciation and budget of the East China Sea. Continental Shelf Research 24, 1285-1299.

Gong, G.C., Shiah, F.K., Liu, K.K., Wen, Y.H., Liang, M.H., 2000. Spatial and temporal variation of chlorophyll a, primary productivity and chemical hydrography in the southern East China Sea. Continental Shelf Research 20, 411-436. 
Graham, W.F., Duce, R.A., 1979. Atmospheric pathways of the phosphorus cycle. Geochemica et Cosmochimica Acta A 43, 1195-1208.

Herut, B., Krom, M.D., Pan, G., Mortimer, R., 1999. Atmospheric input of nitrogen and phosphorus to the southeast Mediterranean: sources, fluxes and possible impact. Limnology and Oceanography 44, 1683-1692.

Huanxin, W., Presley, B.J., Velinsky, D.J., 1997. Distribution and source of phosphorus in tidal river sediments in the Washington, DC, Area. Environmental Geology 30, 224-230.

Markaki, Z., Oikonomou, K., Kocak, M., Kouvarakis, G., Chaniotaki, A., Kubilay, N., Mihalopoulos, N., 2003. Atmospheric deposition of inorganic phosphorus in the Levantine Basin, eastern Mediterranean: spatial and temporal variability and its role in seawater productivity. Limnology and Oceanography 48, 1557-1568.

Migon, C., Sandroni, V., Béthoux, J.-P., 2001. Atmospheric input of anthropogenic phosphorus to the northwest Mediterranean under oligotrophic conditions. Marine Environmental Research 52, 413-426.
Murphy, J., Riley, J.P., 1962. A modified single solution method for the determination of phosphate in natural waters. Analytica Chimica Acta 27, 31-36.

Pai, S.C., Yang, C.C., Riley, J.P., 1990. Effects of acidity and molybdate concentration on the kinetics of the formation of the phosphoantimonylmolybdenum blue complex. Analytica Chimica Acta 229, 115-120.

Pan, G., Krom, M.D., Herut, B., 2002. Adsorption-desorption of phosphate on airborne dust and riverborne particulates in East Mediterranean seawater. Environmental Science and Technology 36, 3519-3524.

Ruttenberg, K.C., 1992. Development of a sequential extraction method for different forms of phosphorus in marine sediments. Limnology and Oceanography 37, 1460-1482.

Ruttenberg, K.C., 1993. Reassessment of the oceanic residence time of phosphorus. Chemical Geology 107, 405-409.

Zhang, Y., Zhu, L., Zeng, X., Lin, Y., 2004. The biogeochemical cycling of phosphorus in the upper ocean of the East China Sea. Estuarine, Coastal and Shelf Science 60, 369-379. 